\title{
Analisa Gangguan Gardu Distribusi GT.PUN 03 Perumahan Griya Panakukang Indal Jalan Herstasning Barat
}

\author{
Fita Novianti \\ Teknik Elektro, Politeknik Negeri Ujung Pandang \\ email: Fitanovianti419@yahoo.com
}

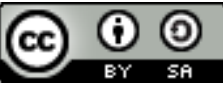

\begin{abstract}
Abstrak
Gardu distribusi merupakan salah satu komponen dari suatu sistem distribusi PLN yang berfungsi untuk menghubungkan jaringan ke konsumen atau untuk mendistribusikan tenaga listrik pada konsumen atau pelanggan, baik itu pelanggan tegangan menengah maupun pelanggan tegangan rendah. Bila terjadi arus lebih pada saluran distribusi dapat menyebabkan kerusakan pada alat-alat listrik karena jika arus kerja bertambah melampaui kapasitas yang ditentukan dan proteksi tidak efektif, maka akan terjadi gangguan dan akan mengakibatkan kerusakan isolasi. Adapun langkah yang dilakukan oleh penulis yaitu dengan pengambilan data menggunakan metode survei, wawancara,observasi dan studi literatur. Penelitian ini difokuskan pada gardu distribusi GT.PUN 03 di perumahan griya panakukang jalan hertasning barat dengan analisis data yang diperoleh menggunakan beberapa persamaan dasar. Dari hasil analisis diketahui penyebab terjadinya terjadinya pemadaman di sebabkan pada Fuse Cut Out yang digunakan pada transformator GT.PUN 03 melampaui dari kapasitas transformator dan NH Fuse yang tidak sesuai dengan spesifikasi transformator sehingga tidak bekerja sebagaimana mestinya mengakibatkan fuse cut out yang berkerja yaitu dengan putusnya fuselink.
\end{abstract}

Kata Kunci: Gardu distribusi, Fuse Cut Out, Fuse Link, NH Fuse

\section{PENDAHULUAN}

Listrik merupakan suatu kebutuhan yang sangat penting bagi manusia. Oleh karena itu, tidaklah berlebihan jika listrik bisa dikatakan sebagai salah satu kebutuhan utama atau pokok bagi penunjang dalam pemenuhan kebutuhan hidup umat manusia. Pemanfaatan secara optimal bentuk energi ini oleh masyarakat dapat dibantu dengan sistem distribusi yang efektif. Oleh karena itu, kualitas kelistrikan sangatlah penting

Gardu distribusi merupakan salah satu komponen dari suatu sistem distribusi PLN yang berfungsi untuk menghubungkan jaringan ke konsumen atau untuk mendistribusikan tenaga listrik pada konsumen atau pelanggan, baik itu pelanggan tegangan menengah maupun pelanggan tegangan rendah. Dalam Gardu Distribusi ini biasanya digunakan transformator distribusi yang berfungsi untuk menurunkan tegangan listrik dari jaringan distribusi tegangan tinggi menjadi tegangan terpakai pada jaringan distribusi tegangan rendah.[1].

Gangguan biasanya diakibatkan oleh kegagalan isolasi di antara penghantar phasa atau antara penghantar phasa dangan tanah. Secara nyata kegagalan isolasi dapat menghasilkan beberapa efek pada sistem yaitu menghasilkan arus yang cukup besar, atau mengakibatkan adanya impedansi diantara konduktor phasa atau antara penghantar phasa dan tanah. Adapun kondisi yang terjadi di perumahan griya panakukang indah yaitu beberapa kali terjadi pemadaman listrik secara singkat atau dalam waktu yang tidak lama. Oleh karena itu penulisis ingin melakukan penelitian tentang "analisa gangguan pada gardu distribusi GT.PUN 03 Perumahan Griya panakukang indah jalan hertasning barat".

\section{KAJIAN LITERATUR}

A. Sistem Distribusi Tenaga Listrik

Sistem distribusi merupakan bagian dari sistem tenaga listrik. Sistem distribusi ini berguna untuk menyalurkan tenaga listrik dari pembangkit sampai ke konsumen. Tenaga listrik yang dihasilkan oleh pembangkit tenaga listrik besar dengan tegangan dari $11 \mathrm{kV}$ sampai $24 \mathrm{kV}$ dinaikan tegangannya oleh Gardu Induk (GI) dengan transformator step-up menjadi $70 \mathrm{kV}, 154 \mathrm{kV}, 220 \mathrm{kV}$ atau 500 $\mathrm{kV}$ kemudian disalurkan melalui saluran transmisi. [1]. 
Sistem Distribusi dimulai dari Gardu Induk dimana tegangan tinggi diturunkan menjadi tegangan menengah sebesar $20 \mathrm{KV}$ yang disebut tegangan distribusi primer. Kemudian tenaga listrik disalurkan melalui penyulang-penyulang yang berupa saluran udara ataupun saluran kabel bawah tanah. Pada penyulang distribusi ini terdapat gardu-gardu distribusi. Fungsi Gardu Distribusi ini menurunkan Tegangan Distribusi Primer menjadi Tegangan Rendah atau Tegangan Distribusi Sekunder sebesar 220 V. Konsumen tenaga listrik disambung dari Jaringan Tegangan Rendah(JTR) melalui Saluran Rumah(SR). Dari SR, tenaga listrik masuk ke Alat Pembatas dan Pengukur (APP) terlebih dahulu sebelum memasuki Instalasi rumah milik konsumen. APP berfungsi membatasi daya dan mengukur pemakaian energi listrik oleh konsumen [2]

\section{B. $\quad$ Gardu Distribusi Listrik}

Gardu distribusi adalah sebuah komponen penting dalam penyaluran distribusi listrik yang berfungsi untuk menurunkan tegangan dari tegangan menengah ke tegangan rendah untuk disalurkan dan digunakan oleh pelanggan. Di dalam gardu distribusi terdapat beberapa peralatan listrik seperti panel hubung bagi (PHB) TM, (PHB) TR, dan transformator distribusi (20kV/380 volt). Pada PHB-TM ada FCO (fuse cut out), arrester (penangkap petir) dan lain-lain. Pada PHB-TR ada NH fuse, rel, headbump dan lain-lain. [1]

Secara garis besar gardu distribusi dibagi kedalam beberapa jenis menurut pemasanganya, kontruksinya, dan penggunaannya. Menurut pemasangannya gardu distribusi dibagi menjadi gardu pasangan dalam (gardu beton / gardu tembok dan gardu kios) dan pasangan luar (gardu portal dan gardu cantol). Menurut penggunaannya ada gardu penggunaan umum (untuk banyak pelanggan listrik tegangan rendah yang biasa ada di sekitar rumah) dan gardu penggunaan khusus (untuk satu pelanggan tegangan menengah yang memakai daya minimal $200 \mathrm{kVA}$ ). Karena pada dasarnya jenis gardu distribusi sama saja baik menurut pemasangan, konstruksi maupun penggunaan, Berikut adalah gambar kontruksi gardu tipe portal, yaitu
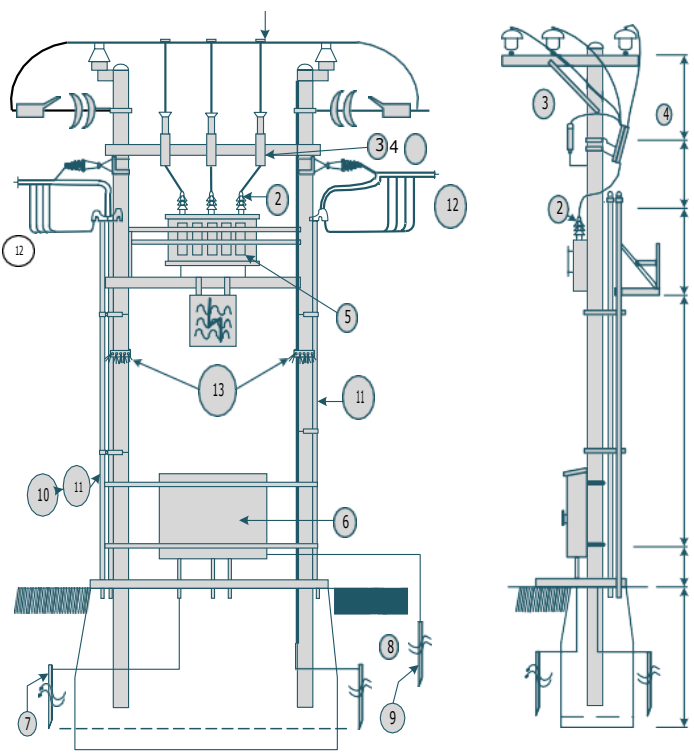

Gambar 2. 1 gambar kontruksi gardu tipe portal

Keterangan :

1. Parallel Grove (Live-Line-Connector)

2. Bimetal Al-Cu-Lug

3. Laghting Arrester-Le

4. Fused Cut Out

5. Transformator

6. $\mathrm{Phb}-\mathrm{Tr}$

7. Elektroda Bumi Titik Netral

Transformator

8. Elektroda Bumi Dan La

9. Elektroda Bumi Bkt

10. Pipa Gal Vanis $41 \mathrm{Mcl}$

11. Pipa Gal Vanis $5 / 8 \mathrm{Mcl}$

12. Jaringan $\mathrm{Tr}$

13. Ranjau Panjat

\section{Transformator}

Transformator merupakan alat yang memegang peran penting dalam sistem distribusi. Transformator distribusi mengubah tegangan menengah menjadi tegangan rendah. Sebagaimana halnya dengan komponenkomponen lain dari rangkaian distribusi, rugirugi energi dan turun tegangan yang disebabkan arus listrik yang mengalir menuju beban. Sehingga harus dilakukan penentuan untuk pemilihan dan lokasi transformator. [1]

\section{Gangguan Pada jaringan distribusi}

Berdasarkan ANSI/IEEE Std. 100-1992 gangguan didefenisikan sebagai suatu kondisi fisis yang disebabkan kegagalan suatu perangkat, komponen atau suatu elemen untuk bekerja sesuai dengan fungsinya. Gangguan hampir selalu ditimbulkan oleh hubung 
singkat antar fase atau hubung singkat fase ke tanah. Suatu gangguan hampir selalu berupa hubung langsung atau melalui impedansi. Istilah gangguan identik dengan hubung singkat, sesuai standart ANSI/IEEE Std. 1001992. Hubung singkat merupakan suatu hubungan abnormal (termasuk busur api) pada impedansi yang relatif rendah terjadi secara kebetulan atau disengaja antara dua titik yang mempunyai potensial yang berbeda. Istilah gangguan atau gangguan hubung singkat digunakan untuk menjelaskan suatu hubungan singkat.

E. Komponen pengaman gardu distribusi Untuk menjaga gardu distribusi tetap bekerja secara optimal sebaiknya digunakan beberapa komponen pengaman. Adapun komponen-komponen pengamannya yaitu Fuse Cut Out, Lightning Arrester, panel tegangan rendah, saklar pemutus utama, $\mathrm{NH}$ Fuse.

a. Sistem Proteksi pada Transformator

Tujuan utama proteksi adalah untuk mencegah terjadinya gangguan atau memadamkan gangguan yang telah terjadi dan melokalisirnya, dan membatasi pengaruhpengaruhnya, biasanya dengan mengisolir bagian-bagian yang terganggu tanpa mengganggu bagian-bagian yang lain. Adapun perlindungan pada transformator yaitu FCO dan Arrester.

\section{Fuse cut out (FCO)}

FCO merupakan sebuah alat pemutus rangkaian listrik yang berbeban pada jaringan distribusi yang bekerja dengan cara meleburkan bagian dari komponennya (fuse link) yang telah dirancang khusus dan disesuaikan ukurannya untuk itu. Perlengkapan fuse ini terdiri dari sebuah rumah fuse (fuse support), pemegang fuse (fuse holder) dan fuse link sebagai pisau pemisahnya. Adapun gambar dibawah ini merupakan bagian utama dari FCO.

2. Menentukan Fuse Link pada FCO Fuse Link adalah komponen pengaman kelistrikan yang berfungsi sebagai pengaman arus lebih dan hubung singkat pada tegangan menengah dan juga digunakan pada pengaman transformator. Sebenarnya Fuse Link memiliki fungsi yang sama dengan fuse lainnya, yang membedakan hanya kapasitasnya. Di dalam Fuse Link terdapat kawat lebur yang berfungsi sebagai penghantar arus dan juga sebagai pengaman dari beban lebih dan hubung singkat. Apabila terjadi arus lebih atau hubung singkat, kawat lebur tersebut akan mengalami kenaikan suhu dan akan melebur (putus), sehingga arus listrik yang melalui fuse link akan terputus. Apabila kawat lebur sudah terputus maka fuse tidak berfungsi dan harus diganti. Adapun cara menentukan Fuse Link adalah dengan persamaan (1), sebagai berikut:

Fuse Link =

$$
\frac{\text { kapasitas transformator }(\mathrm{kVA})}{\sqrt{3} \times \text { Tegangan } \mathrm{TM}(\mathrm{V})}
$$

a. Sistem Proteksi pada Gardu Distribusi

Pada dasarnya semua konstruksi jaringan distribusi tidak ada yang benarbenar aman dari gangguan yang datangnya dari dalam sistem itu sendiri maupun dari dari luar sistem. Gangguan tersebut merupakan potensi yang merugikan ditinjau dari beberapa hal, maka perlunya dipasang sistem proteksi yang berfungsi untuk mencegah atau membatasi kerusakan pada gardu beserta peralatannya dan menjaga keselamatan umum

Pada sistem distribusi $20 \mathrm{kV}$ hal yang terpenting pada sistem proteksi selain alat proteksi itu sendiri, sistem pentanahan juga merupakan bagian yang tidak terpisahkan dalam sistem proteksi itu sendiri. Misalnya ada gangguan fasa yang bocor ke tanah, maka bila sistem pentanahan tidak sesuai dengan sistem distribusi yang diproteksi, maka alat proteksi tidak akan bekerja dengan benar, sehingga dapat merusak peralatan jaringan maupun membahayakan keselamatan manusia. Adapun pengaman pada gardu distribusi yaitu NH Fuse dan Pentahanan.

b. Cara menentukan kapasitas NH Fuse pada gardu distribusi

NH Fuse berfungsi untuk membatasi arus jurusan dan sebagai pengaman jika terjadi beban lebih atau hubung singkat pada jaringan tegangan rendah. NH Fuse berada di dalam panel tegangan rendah. Adapun caranya dengan rumus persamaan (2), sebagai berikut [3]:

$$
\text { In }=\frac{\text { kapasitas transformator }(\mathrm{kVA})}{\sqrt{3} \times \text { tegangan }}
$$

Setelah mendapatkan hasil dari menentukan $\mathrm{NH}$ fuse pada gardu distribusi selanjutnya dibagi dengan jurusannya. Berikut contoh gambar dari NH Fuse yang dapat dilihat pada gambar dibawah ini: 


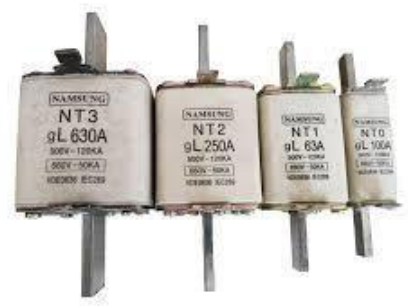

Gambar 2.2 NH Fuse

Untuk mengetahui persentase kapasitas transformator digunakan rumus persamaan (3), yaitu[3]:

$\%=\frac{\text { beban pelanggan yang terpasang }(\mathrm{kVA})}{\text { kapasitas trafo }(\mathrm{kVA})} \times$

Tabel 1.Kapasitas daya Transformator dan NH Fuse

\begin{tabular}{|c|c|c|c|c|c|}
\hline \multicolumn{2}{|c|}{$\begin{array}{l}\text { Transformator } \\
\text { Distribusi }\end{array}$} & \multicolumn{2}{|c|}{$\begin{array}{c}\text { Pelebur } \\
\text { primer/tipe arus } \\
\text { pengenal }(\mathrm{A})\end{array}$} & \multicolumn{2}{|c|}{$\begin{array}{l}\text { Pelebur sekunder } \\
\text { arus pengenal }(A)\end{array}$} \\
\hline $\begin{array}{l}\text { Daya } \\
\text { penge } \\
\text { nal } \\
(\mathrm{kVA})\end{array}$ & $\begin{array}{l}\text { Arus } \\
\text { penge } \\
\text { nal }(A)\end{array}$ & $\begin{array}{c}\text { Minim } \\
\text { um }\end{array}$ & $\begin{array}{l}\text { Maksim } \\
\text { um }\end{array}$ & $\underset{\text { um }}{\text { Minim }}$ & $\begin{array}{l}\text { Maksim } \\
\text { um }\end{array}$ \\
\hline 1 & 2 & 3 & 4 & 5 & 6 \\
\hline \multicolumn{6}{|c|}{ Fasa tunggal, $\frac{2 \mathrm{U}}{\sqrt{3}} \mathrm{kV}$} \\
\hline 16 & 1,3856 & $2 \mathrm{H}$ & $2 \mathrm{H}$ & 80 & 100 \\
\hline 25 & 2,1651 & $3,15 \mathrm{H}$ & $3,15 \mathrm{H}$ & 125 & 125 \\
\hline 50 & 4,3301 & $5 \mathrm{H}$ & $6,3 \mathrm{~T}$ & 250 & 250 \\
\hline \multicolumn{6}{|c|}{ Fasa tiga , $20 \mathrm{kV}$} \\
\hline 50 & 1,4434 & $2 \mathrm{H}$ & $2 \mathrm{H}$ & 80 & 100 \\
\hline 100 & 2,8867 & $5 \mathrm{H}$ & $6,3 \mathrm{~K} ; 6,3 \mathrm{~T}$ & 160 & 200 \\
\hline 160 & 4,6188 & $6,3 \mathrm{~T}$ & $8 \mathrm{~K} ; 8 \mathrm{~T}$ & 250 & 250 \\
\hline 200 & 5,7735 & $6,3 \mathrm{~T}$ & $10 \mathrm{~K} ; 10 \mathrm{~T}$ & 315 & 315 \\
\hline 250 & 7,2169 & $8 \mathrm{~T}$ & $\mathrm{~L} 2,5 \mathrm{~K} ; 12,5 \mathrm{~T}$ & 400 & 400 \\
\hline 315 & 9,0933 & $10 \mathrm{~T}$ & $2,5 \mathrm{~K} ; 12,5 \mathrm{~T}$ & 500 & 500 \\
\hline 400 & 11,547 & $12,5 \mathrm{~T}$ & $16 \mathrm{~K} ; 16 \mathrm{~T}$ & 630 & 630 \\
\hline 500 & 14,4337 & $16 \mathrm{~T}$ & $20 \mathrm{~K} ; 20 \mathrm{~T}$ & 800 & 800 \\
\hline 630 & 8,1865 & $20 \mathrm{~T}$ & $25 \mathrm{~K} ; 25 \mathrm{~T}$ & 1000 & 1000 \\
\hline 800 & 23,094 & $25 \mathrm{~T}$ & $1,5 \mathrm{~K} ; 31,5 \mathrm{~T}$ & 1250 & 1250 \\
\hline 1000 & 8,8675 & $31,5 \mathrm{~T}$ & $40 \mathrm{~K} ; 40 \mathrm{~T}$ & 1600 & 1600 \\
\hline
\end{tabular}

Sumber : [3] PLN-d3026-2017

\subsection{System Average Interruption Duration Index (SAIDI)}

Indeks ini didefinisikan sebagai nilai ratarata dari lamanya kegagalan untuk setiap konsumen selama satu tahun. Indeks ini ditentukan dengan pembagian jumlah dari lamanya kegagalan secara terus menerus untuk semua pelanggan selama periode waktu yang telah ditentukan dengan jumlah pelanggan yang dilayani selama tahun itu. Persamaan untuk SAIDI (rata-rata jangka waktu gangguan setiap pelanggan) ini dapat dilihat pada persamaan 5 dibawah ini. [4].

SAIDI $\sum U_{i}$.

C...............

Dengan :

$U_{\mathrm{i}}=$ total custumer pada satu sistem distribusi

$C_{i}=$ durasi perbaikan (repair duration)

\subsection{System Average Interruption Frequency Index (SAIFI)}

Indeks ini didefinisikan sebagai jumlah ratarata kegagalan yang terjadi per pelanggan yang dilayani oleh sistem per satuan waktu (umumnya per tahun). Indeks ini ditentukan dengan membagi jumlah semua kegagalan-pelanggan dalam satu tahun dengan jumlah pelanggan yang dilayani oleh sistem tersebut. Persamaan untuk SAIFI (rata-rata jumlah gangguan saban pelanggan) ini dapat dilihat pada persamaan dibawah ini. [4].

SAIFI $\frac{\sum c_{i}}{\sum N_{i}}$

Dengan :

$C_{i}=$ total custumer pada satu sistem distribusi

$N_{i}=$ durasi perbaikan (repair duration)

\section{METODE PENELITIAN}

A. Tempat dan Waktu Penelitian

Penelitian ini dilaksanakan di

PT.PLN (Persero) Area Makassar Rayon

Panakukang, tempat ini merupakan sumber data bagi penulis

Penelitian dan pengambilan data berlangsung selama 4 bulan yang dilaksanakan mulai pada bulan Februari - Mei 2019.

\section{B. Prosedur Penelitian}

Prosedur kegiatan pada tugas akhir ini dimulai dengan melakukan survei lapangan, dengan melihat keadaan gardu distribusi yang akan dilakukan pengukuran. Kemudian mengambil data pada PT. PLN (Persero) rayon panakukang dan melakukan penelitian pada gardu distribusi.

C. Metode Pengumpulan data

1. Survei

Survei adalah melakukan kunjungan atau pengamatan langsung di PT. PLN (Persero) rayon panakukang, untuk mengetahui kondisi real dan mendapatkan data-data yang diperlukan dan informasi penting lainnya dalam penyusunan tugas akhir ini.

2. Wawancara 
Metode pengumpulan data ini dilakukan dengan mengadakan tatap muka atau wawancara secara langsung dengan pimpinan perusahaan atau orang-orang yang mempunyai pengetahuan yang ada kaitannya dengan penyusunan tugas akhir ini.

3. Observasi

Obsevasi bertujuan mengamati perubahan dan hal-hal yang terjadi pada saat mengumpulkan data.

4. Studi Literatur

kegiatan ini dilakukan dengan mengadakan studi dari buku-buku/pustaka, situs-situs internet dan literatur lain yang berkaitan dengan masalah yang dibahas dalam penulisan skripsi ini.

D. Metode Analisis Data

Pengumpulan data dilakukan dengan tiga metode yang dijelaskan sebelumnya.

\section{HASIL DAN PEMBAHASAN}

Gardu GT. PUN 03 Jl. Hertasning Barat PT. PLN (Persero) Area Makassar selatan ULP (unit pelayanan pelanggan) panakukang penyulang UNM di suplai dari gardu induk Panakukkang 150 $\mathrm{kV}$. Pada penyulang Alauddin terdapat 24 gardu transformator yang dilayani, salah satu adalah GT.PUN 03 di perumahan griya panakukang indah Jl. Hertasning barat. Gardu GT. PUN 03 terdapat 3 saluran dan melayani kurang lebih 140 pelanggan.

Setelah melakukan penelitian mengenai penyebab terjadinya pemadaman listrik pada gardu distribusi GT. PUN 03 diketahui gangguan berasal dari FCO yang meledak dan mengakibatkan perumahan mengalami trip karena putusnya tegangan. FCO merupakan sebuah alat pemutus rangkaian listrik yang berbeban pada jaringan distribusi yang bekerja dengan cara meleburkan bagian dari komponennya (fuse link) yang telah dirancang khusus dan disesuaikan ukurannya untuk itungan ke konsumen.

Tabel 2. Data transformator

\section{DATA TRANSFORMATOR}

\begin{tabular}{cc}
\hline Merk & Trafindo \\
\hline Daya & $400 \mathrm{kVA}$ \\
\hline Frekuensi & $50 \mathrm{~Hz}$ \\
\hline
\end{tabular}

http://dx.doi.org/10.31963/elekterika.v3i2.1557

\begin{tabular}{cc} 
Tegangan & $20000 \mathrm{~V}$ \\
\hline Impedansi $(\mathrm{Z})$ & $4,0 \%$ \\
\hline Berat total & $1230 \mathrm{~kg}$ \\
\hline
\end{tabular}

Tabel 3. Data NH Fuse

\section{DATA FUSELINK}

\begin{tabular}{cc}
\hline Merk & $\begin{array}{c}\text { PT.SINARINDO WIRANUSA } \\
\text { ELEKTRIK }\end{array}$ \\
\hline Type & SP 100 A \\
\hline Kapasitas & 12 Ampere \\
\hline
\end{tabular}

Tabel 4. Data NH-fuse

\begin{tabular}{|c|c|c|c|c|c|}
\hline \multicolumn{6}{|c|}{ DATA NH FUSE } \\
\hline Saluran & 1 & 2 & 3 & 4 & 5 \\
\hline Merk & ETI & LINDER & $\begin{array}{c}\text { KEARNE } \\
\mathrm{Y} \\
\end{array}$ & LINDER & $\begin{array}{c}\text { LIND } \\
\text { ER } \\
\end{array}$ \\
\hline Type & NV 2 & NT 1 & NT 2 & NT 1 & NT 1 \\
\hline Kapasitas & $355 \mathrm{~A}$ & $250 \mathrm{~A}$ & $355 \mathrm{~A}$ & $200 \mathrm{~A}$ & $200 \mathrm{~A}$ \\
\hline Saluran & 6 & 7 & 8 & 9 & \\
\hline Merk & $\begin{array}{c}\text { LIND } \\
\text { ER } \\
\end{array}$ & $\begin{array}{c}\text { KEARNE } \\
\mathrm{Y} \\
\end{array}$ & LINDER & LINI & \\
\hline Type & NT 1 & NT 1 & NT 1 & NT & \\
\hline Kapasitas & $250 \mathrm{~A}$ & $250 \mathrm{~A}$ & $250 \mathrm{~A}$ & 250 & \\
\hline
\end{tabular}

\subsection{Menentukan Fuse Link pada FCO}

Untuk menentukan Fuse Link pada FCO digunakan rumus persamaan (1) yaitu :

Fuse Link $=\frac{\text { kapasitas transformator }(\mathrm{kVA})}{\sqrt{3} \times \text { Tegangan TM }(\mathrm{V})}$

$$
\begin{aligned}
& \text { Kapasitas : } 400 \mathrm{kVA}=400.000 \text { Volt } \\
& \begin{aligned}
\text { Ampere } & : 20 \mathrm{KV}=20.000 \text { Volt } \\
\text { Tegangan TM } & : 3 \text { Fasa } \\
\text { Jenis Transformator } & \\
\text { Fuse Link } & =\frac{400000}{\sqrt{3 \times 20000}} \\
& =\frac{400000}{34600} \\
& =11,56 \mathrm{~A}
\end{aligned}
\end{aligned}
$$

Berdasar hasil perhitungan diatas yaitu sebesar 11,56 Ampere. Karena tidak terdapat kapasitas Fuse Link sebesar 11,56 Ampere maka dilakukan pembulatan nilai kapasitas Fuse Link yang digunakan sebesar 12 Ampere. Hasil dari perhitungan dan kapasitas fuse link yang terpasang di GT.PUN 03 sama. Namun apa bila terjadi kelebihan arus dari kapasitas 12 Ampere fuse link maka akan terjadi pemutusan fuse link. Dalam Fuse Link terdapat kawat lebur yang berfungsi sebagai penghantar arus dan juga sebagai pengaman dari beban lebih dan hubung singkat. Apabila terjadi 
arus lebih atau hubung singkat, kawat lebur tersebut akan mengalami kenaikan suhu dan akan melebur (putus), sehingga arus listrik yang melalui fuse link akan terputus. Apabila kawat lebur sudah terputus maka fuse tidak berfungsi dan harus diganti. Berikut adalah gambar single line gardu distribusi, yaitu :

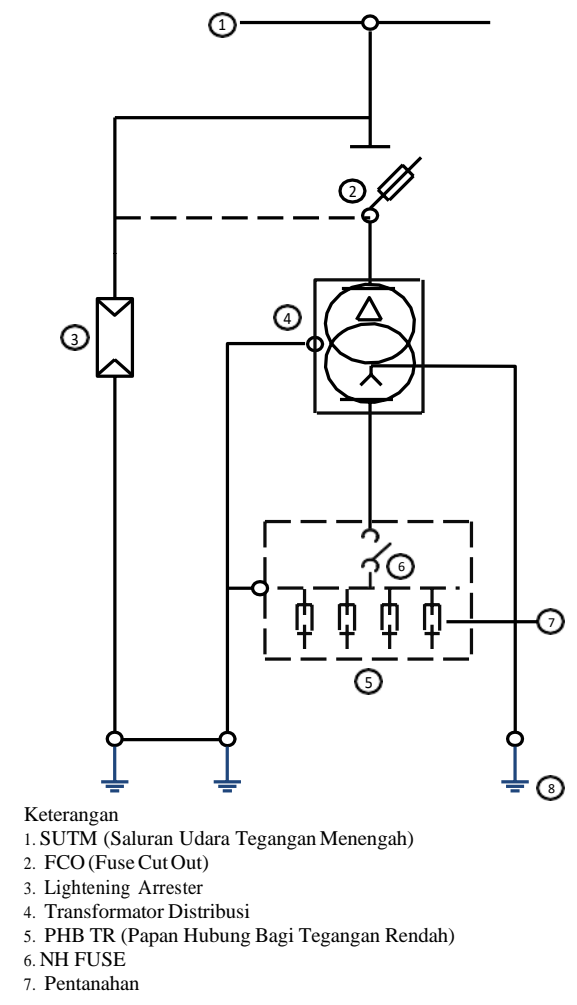

Gambar 16. Single Line gardu distribusi GT.PUN 03

4. 2 Menentukan kapasitas NH Fuse untuk Jaringan Distribusi

Untuk menentukan kapasitas NH Fuse

untuk jaringan distribusi digunakan rumus

persamaan (2), yaitu:

$n=\frac{\text { kapasitas transformator }(\mathrm{kVA})}{\sqrt{ } 3 \times \text { tegangan }}$

Kapasitas Transformator : $400 \mathrm{kVA}$

Tegangan : $20 \mathrm{KV} / 231$ 400

$$
\begin{aligned}
& \text { Jumlah Jurusan } \\
& \begin{array}{l}
\text { In }=\frac{400000}{\sqrt{3} \times 400} \\
=\frac{400000}{1,732 \times 400} \\
=\frac{400000}{692,8} \\
=577,35 \mathrm{~A}
\end{array}
\end{aligned}
$$
3

Arus tiap jurusan $=\frac{577,35}{3}$

$$
=192,45 \mathrm{~A}
$$

Berdasarkan perhitungan NH Fuse diatas, maka diperoleh nilai arus NH Fuse tiap jurusannya sebesar 192,45 Ampere. Namun berdasarkan data
NH Fuse yang terpasang di tiap jurusannya berbeda-beda. Pada fasa $\mathrm{R}$ yang terpasang jurusan pertama sebesar 355 Ampere, jurusan dua sebesar 250 Ampere, jurusan tiga sebesar 355 Ampere. Pada fasa $\mathrm{S}$ jurusan empat sebesar 200 Ampere, jurusan lima sebesar 200 Ampere, jurusan enam 250 Ampere. Pada fasa T jurusan tujuh sebesar 250 Ampere, jurusan delapan sebesar 250 Ampere, jurusan sembilan sebesar 250 Ampere. Karena NH Fuse yang terpasang berbeda beda kapasitasnya bahkan pada jurusan pertama mencapai 355 Ampere, jika berdasarkan perhitungan hanya 192,45 Ampere maka hal ini mengakibatkan NH Fuse melebihi kapasitasnya dan tidak bisa berjalan sebagaimana mestinya sehingga pengaman pada tegangan menengah yaitu FCO yang berkerja yaitu dengan putusnya fuse link.

Maka, Sebaiknya besar kapasitas tiap NH Fuse yang terpasang perlu penyetaraan kapasitas agar terjadi keseimbangan beban pada transformator.

4.3.Perhitungan persentase kapasitas transformator Menentukan persentase kapasitas transformator menggunakan rumus persamaan (3) :

$$
\begin{gathered}
\%=\frac{\text { beban pelanggan yang terpasang }(\mathrm{kVA})}{\text { kapasitas trafo }(\mathrm{kVA})} \\
\quad \times 100 \%
\end{gathered}
$$

Berdasarkan perhitungan diatas didapatkan hasil persentase kapasitas transformator melebihi $3,25 \%$ dari batas kapasitas transformator yang terpasang pada GT.PUN 03. Hal ini mengakibatkan putusnya fuse link dikarenakan beban yang tersambung melampaui kapasitas pada fasa tertentu dan dari aturan yang sebenarnya di $\mathrm{NH}$ fuse sehingga beban transformator melampaui dari $100 \%$ (overload).

\section{KESIMPULAN}

Dari pembahasan dan perhitungan yang dilakukan pada bab sebelumnya maka dapat diambil kesimpulan antara lain:

1. Penyebab terjadinya pemadaman listrik pada gardu distribusi GT. PUN 03 disebabkan oleh Fuse Cut Out yang melampaui kapasitas transformator yaitu sebesar 12 Ampere sehingga $\mathrm{NH}$ Fuse sebagai pengaman tidak bisa membatasi arus jurusan karena nilai melebihi kapasitas dan tidak sesuai dengan spesifikasi, sehingga FCO yang berkerja untuk mengamankan transformator pada saat terjadinya gangguan (overload) dengan cara putusnya fuse link. 
2. Untuk mengatasi terjadinya kerusakan FCO, maka perlu dilakukan penyetaraan pada beban yang dilayani, seperti dilakukan managemen transformator dan dilakukan pemeliharaan berupa penyetaraan $\mathrm{NH}$ Fuse

\section{UCAPAN TERIMA KASIH}

UCAPAN TERIMA KASIH

Ucapan terima kasih ditujukan kepada :

1 Kedua orang tua atas segala doa, pengorbanan, motivasi, kasih sayang yang menjadi penggugah semangat penulis.

2. Dosen pembimbing $1 \mathrm{Ir}$. Hamma, M.T.dan pembimbing Marwan, S.T., M.Eng, Sc., Ph.D.

3. Staff PLN yang telah membantu dan menyediakan waktu luangnya dalam pengambilan data.

4. Teman-teman kelas yang sudah membantu dalam belajar.

\section{REFERENSI}

[1] Suhadi dkk. (2008). Teknik Distribusi Tenaga Listrik Jilid 1. Jakarta: Direktorat Pembinaan Sekolah Menengah Kejuruan.

[2] Eemnkharis27. 2013. Sistem tenaga listrik.

[3] SPLN D3.026 :2017. SPESIFIKASI FUSE

CUTOUT.

[4] Oka Widnya, I Md., 2004. Studi Keandalan Penyulang $20 \mathrm{kV}$ di Gardu Induk Padang Sambian Menggunakan Simulasi Monte Carlo. Jimbaran : Teknik Elektro Universitas Udayana 